\title{
Polymorphisms in thymidylate synthase gene and susceptibility to breast cancer in a Chinese population: a case-control analysis Xiangjun Zhai1,3, Jun Gao1,2, Zhibin $\mathrm{Hu}^{1,2}$, Jinhai Tang ${ }^{4}$, Jianwei Qin ${ }^{4}$, Shui Wang5 ${ }^{5}$ Xuechen Wang ${ }^{6}$, Guangfu Jin², Jiyong Liu², Wenshen Chen ${ }^{2}$, Feng Chen ${ }^{2}$, Xinru Wang1,2, Qingyi $\mathrm{Wei}^{7}$ and Hongbing Shen*1,2
}

\begin{abstract}
Address: ${ }^{1}$ Laboratory of Reproductive Medicine, Nanjing Medical University, Nanjing 210029, China, ${ }^{2}$ Department of Epidemiology and Nanjing 210009, China, ${ }^{4}$ Department of General Surgery, Jiangsu Cancer Hospital, Nanjing 210009, China, ${ }^{5}$ Department of General Surgery, The First Affiliated Hospital of Nanjing Medical University, Nanjing 210029, China, 'Department of General Surgery, Nanjing Gulou Hospital, Nanjing210009, China and ${ }^{7}$ Department of Epidemiology, The University of Texas M. D. Anderson Cancer Center, Houston, TX 77030, USA

Email: Xiangjun Zhai - xjzhai@tom.com; Jun Gao - GaoJun@eph.org.cn; Zhibin Hu - bbbb0407@sina.com; Jinhai Tang - tanginhai_888@tom.com; Jianwei Qin - jwqin2192@sina.com; Shui Wang - ws0801@hotmail.com; Xuechen Wang - xcwang168@sina.com; Guangfu Jin - guangfujin@sina.com.cn; Jiyong Liu - liuyam@sina.com.cn; Wenshen Chen - metrischen@126.com; Feng Chen - dr.chenfeng@163.com; Xinru Wang - xrwang@njmu.edu.cn; Qingyi Wei - weiqingyi@yahoo.com; Hongbing Shen* - hbshen@njmu.edu.cn

* Corresponding author
\end{abstract} Biostatistics, School of Public Health, Nanjing Medical University, Nanjing 210029, China, ${ }^{3}$ Jiangsu Centers for Diseases Prevention and Control,

Published: 25 May 2006

BMC Cancer 2006, 6:138 doi:10.1 |86/|47|-2407-6-138
Received: 21 December 2005

Accepted: 25 May 2006

This article is available from: http://www.biomedcentral.com//47/-2407/6//38

(C) 2006 Zhai et al; licensee BioMed Central Ltd.

This is an Open Access article distributed under the terms of the Creative Commons Attribution License (http://creativecommons.org/licenses/by/2.0), which permits unrestricted use, distribution, and reproduction in any medium, provided the original work is properly cited.

\begin{abstract}
Background: Accumulative evidence suggests that low folate intake is associated with increased risk of breast cancer. Polymorphisms in genes involved in folate metabolism may influence DNA methylation, nucleotide synthesis, and thus individual susceptibility to cancer. Thymidylate synthase (TYMS) is a key enzyme that participates in folate metabolism and catalyzes the conversion of dUMP to dTMP in the process of DNA synthesis. Two potentially functional polymorphisms [a 28-bp tandem repeat in the TYMS 5'-untranslated enhanced region (TSER) and a 6-bp deletion/insertion in the TYMS 3'-untranslated region (TS 3'-UTR)] were suggested to be correlated with alteration of thymidylate synthase expression and associated with cancer risk.
\end{abstract}

Methods: To test the hypothesis that polymorphisms of the TYMS gene are associated with risk of breast cancer, we genotyped these two polymorphisms in a case-control study of 432 incident cases with invasive breast cancer and 473 cancer-free controls in a Chinese population.

Results: We found that the distribution of TS3'-UTR (I494del6) genotype frequencies were significantly different between the cases and controls $(P=0.026)$. Compared with the TS3'-UTR del6/del6 wild-type genotype, a significantly reduced risk was associated with the ins6/ins 6 homozygous variant genotype (adjusted $O R=0.58$, $95 \% \mathrm{Cl}=0.35-0.97)$ but not the del6/ins6 genotype $(\mathrm{OR}=1.09,95 \% \mathrm{Cl}=0.82-1.46)$. Furthermore, breast cancer risks associated with the TS3'-UTR del6/del6 genotype were more evident in older women, postmenopausal subjects, individuals with a younger age at first-live birth and individuals with an older age at menarche. However, there was no evidence for an association between the TSER polymorphism and breast cancer risks.

Conclusion: These findings suggest that the TS3'-UTR del6 polymorphism may play a role in the etiology of breast cancer. Further larger population-based studies as well as functional evaluation of the variants are warranted to confirm our findings. 


\section{Background}

Breast cancer is the leading cause of cancer-related deaths for women in China, and the incidence rate is still increasing [1]. A wide diversity of genetic damage induced by endogenous metabolites and exogenous hazards may contribute to the etiology of breast cancer. Epidemiological studies suggested that folate-deficient diet may increase the risk for breast cancer [2-5]. Folate, often in the form of folic acid, is essential for DNA methylation, DNA synthesis, and DNA repair [6,7]. Chronic folate/methyl deficiency in vivo and in vitro has been associated with DNA strand breaks [8-10] and abnormal DNA methylation $[11,12]$ that may lead to carcinogenesis.

Many enzymes are involved in folate metabolism, among which, thymidylate synthase (TYMS) catalyzes the conversion of deoxyuridine monophosphate (dUMP) to deoxythymidine monophosphate (dTMP), using the 5, 10methylenetetrahydrofolate as a methyl donor [13]. This conversion is essential for the provision of thymidine, a nucleotide needed for DNA synthesis and DNA repair [14]. In thymidylate synthase-negative mutants of mouse FM3A cells, thymidine starvation results in thymineless death via the induction of DNA double-strand breaks that lead to chromosome fragmentation as well as rearrangements in the cells synthesizing DNA [15]. Therefore, genetic alterations in TYMS enzyme efficiency and/or expression level may contribute to individual susceptibility to breast cancer.

The TYMS gene is located in chromosome 18p11.32. A tandem repeat polymorphism has been identified in the 5 '-UTR enhancer region of the TYMS promoter (TSER), the immediate upstream of the ATG codon initiation start site, which contains triple (TSER 3R) or double (TSER 2R) repeats of a 28-bp sequence as well as several rare alleles containing 4, 5 or 9 repeats [16]. In vitro and in vivo studies showed that TYMS expression was TSER genotypedependent and that the $3 R$ allele was associated with a higher TYMS expression level [16,17]. Recently, a novel polymorphism, a 6-bp deletion/insertion in the 3'untranslated region of the TYMS gene (TS3'-UTR del6), has also been identified, which may have an effect on the TYMS mRNA stability and translation [18], perhaps affecting TYMS protein expression level as well. Therefore, the above two TYMS variants are thought to be functionally relevant and are hypothesized to be associated with risk of breast cancer. To test this hypothesis, we performed genotyping analyses for TS 5'-UTR TSER and TS 3'-UTR del6 polymorphisms in a case-control study of 432 incident cases with invasive breast cancer and 473 cancer-free controls in a Chinese population.

\section{Methods \\ Study population}

This hospital-based case-control study consisted of 432 patients who received surgical treatment for solitary mammary lumps, which were histopathologically diagnosed as invasive breast cancer, and 473 cancer-free controls. All subjects were genetically-unrelated ethnic Han Chinese and were from Nanjing city and surrounding regions in Jiangsu Province. The breast cancer patients were consecutively recruited between January 2004 and July 2005 at the Cancer Hospital of Jiangsu Province, the First Affiliated Hospital of Nanjing Medical University and the Nanjing Gulou Hospital, Nanjing, China. Those patients who had any previous cancers, in situ breast cancer (DCIS), metastasized cancer originated from other organs, and previous radiotherapy or chemotherapy were excluded. Cancer-free controls were randomly selected from a pool of 10,500 individuals who participated in a communitybased screening program for non-infectious diseases conducted in Jiangsu Province during the same time period as the cases were recruited. These control subjects had no self-reported cancer history and were frequency-matched to the cases on age ( \pm 5 years) and residential areas. Each subject was scheduled for an interview after an informed consent was obtained, and a structured questionnaire was administered by interviewers to collect information on demographic data, menstrual and reproductive history, family history of cancer (any kind of cancers in firstdegree relatives) and environmental exposure history. After the interview, an approximately 5-ml venous blood sample was collected from each subject. The study was approved by the institutional review board of Nanjing Medical University.

\section{Genotype analyses}

By centrifugation of 5-ml whole blood, genomic DNA was extracted from the leukocyte pellet obtained from the buffy coat of each blood sample. We used the previouslydescribed genotyping assays for the two loci of TYMS [19]. Briefly, we used pairs of primers of 5'-GTGGCTCCTGCGTTTCCCCC-3' (forward) and 5'-GGCTCCGAGCCGGCCACAGGCATGGCGCGG-3' (reverse) to genotype the TSER locus and 5'-CAAATCTGAGGGAGCTGAGT-3' (forward) and 5'-CAGATAAGTGGCAGTACAGA-3' (reverse) to genotype the TS 3'-UTR del6 locus. For the TSER polymorphism, 243 bp (i.e. 3R), 215 bp (i.e. 2R), 271 bp (i.e. $4 \mathrm{R}$ ) and 299 bp (i.e. 5R) fragments were identified and separated on 3\% agarose gels. For the TS 3'-UTR del6 polymorphism, 152 bp (i.e. del6) or 158 bp fragments (i.e. ins6) were amplified and then digested by Dra I (New England BioLabs, Inc., Beverly, MA). The variant (ins6) allele produces two fragments of 88 and $70 \mathrm{bp}$, while the wild-type (del6) allele produces a single 152-bp fragment. Genotyping was performed without knowing the subjects' case or control status, and approximately equal number of 
Table I: Comparison of breast cancer cases and controls by selective characteristics

\begin{tabular}{|c|c|c|c|}
\hline Variable & Controlsc $^{c}(n=473)$ & Breast cancer $(n=432)$ & $P$ value \\
\hline Age, yr (mean \pm SD) & $51.42 \pm 11.12$ & $52.09 \pm 11.03$ & 0.36 \\
\hline Age at menarche, yr (mean $\pm S D)$ & $16.40 \pm 1.77$ & $15.32 \pm 1.92$ & $<0.0001$ \\
\hline Age at first live birth, $y r$ (mean $\pm S D)$ a & $24.49 \pm 2.47$ & $25.51 \pm 3.45$ & $<0.0001$ \\
\hline Age at menopausal, yr (mean $\pm S D)$ & $49.79 \pm 3.88$ & $48.89 \pm 4.26$ & 0.02 \\
\hline $\mathrm{BMI}$ & $23.69 \pm 3.35$ & $23.95 \pm 3.55$ & 0.25 \\
\hline Menopausal status & & & 0.74 \\
\hline Premenopausal & $210(44.4)$ & $197(45.6)$ & \\
\hline Postmenopausal & $263(55.6)$ & $235(54.4)$ & \\
\hline Family History of Cancer & & & 0.033 \\
\hline Positive & $95(20.1)$ & $113(26.2)$ & \\
\hline Negative & $378(79.9)$ & $319(73.8)$ & \\
\hline TSER & & & 0.987 \\
\hline $3 R$ allele & $753(79.6)$ & $688(79.8)$ & \\
\hline $2 \mathrm{R}$ allele & $193(20.4)$ & $176(20.2)$ & \\
\hline TS 3'-UTR del6 & & & 0.347 \\
\hline del6 allele & $633(66.9)$ & $596(69.0)$ & \\
\hline ins6 allele & $313(33.1)$ & $268(31.0)$ & \\
\hline Haplotypes of TSER and TS 3'-UTR del6 polymorphisms & & & 0.863 \\
\hline 3R-del6 & $295(62.4)$ & $27 I(62.6)$ & \\
\hline $3 R$-ins 6 & $83(17.5)$ & $73(17.0)$ & \\
\hline 2R-del6 & $25(5.3)$ & $28(6.4)$ & \\
\hline $2 R$-ins6 & $70(\mid 4.8)$ & $60(14.0)$ & \\
\hline
\end{tabular}

a Age at first live birth information was available in 460 controls and 419 breast cancer cases.

b Age at menopausal information was available in 226 controls and 227 breast cancer cases with postmenopausal status.

cThree controls carrying the rare alleles of more than three 28 bp repeats $(>3 R)$ were excluded in the current analyses.

cases and controls were assayed in each 96-well PCR plate with a positive control of a DNA sample with a known heterozygous genotype. If a consensus on the tested genotype was not reached, two research assistants independently performed the repeated assays to achieve 100\% concordance. More than $10 \%$ of the samples were repeated using the same assay and the results were $100 \%$ concordant.

\section{Statistical analyses}

Differences in demographic characteristics, selected variables, and frequencies of the genotypes, alleles, and haplotypes of TSER and TS 3'-UTR del6 between the cases and controls were evaluated using the $\chi^{2}$ test (for categorical variables) and student $t$-test (for continuous variables). The associations between TSER and TS 3'-UTR del6 variant genotypes and breast cancer risk were estimated by computing ORs and their 95\% CIs from both univariate and multivariate logistic regression analyses. Linkage disequilibrium (LD) between the two loci of TYMS was estimated using the EH algorithm available online [20]. We used the PHASE 2.0 program [21] to infer the haplotype frequencies, based on the observed TYMS genotypes. HardyWeinberg equilibrium was tested by a goodness-of-fit $\chi^{2}$ test to compare the observed genotype frequencies with the expected frequencies among the control subjects. All the statistical analyses were performed with Statistical
Analysis System software (v.9.03e; SAS Institute, Cary, NC).

\section{Results}

The selected characteristics and distributions of TSER and TS 3'-UTR del6 alleles/haplotypes of the 432 breast cancer cases and 473 cancer-free controls are summarized in Table 1. The frequency-matching on age between cases and controls was adequate as suggested by a non-significant $p$ value with the student $t$ test. Compared with control subjects, breast cancer patients had a lower age at menarche $(P<0.0001)$ and a higher age at having first live birth $(P<0.0001)$. Among the 498 postmenopausal subjects, the menopausal age of breast cancer cases was lower than that of the controls $(P=0.02)$. There were 113 (26.2\%) breast cancer cases and 95 (20.1\%) controls reported a family history of cancer, which was associated with a significantly increased risk for breast cancer $(\mathrm{OR}=$ $1.41,95 \% \mathrm{CI}=1.03-1.92)$.

The allele frequencies of TSER $2 R$ and TS 3'-UTR ins 6 were 0.204 and 0.331 , respectively, in the controls, while they were 0.202 and 0.310 , respectively, in the cases, and the differences were not statistically significant $(P=0.987$ for TSER and $P=0.347$ for TS 3'-UTR del6) (Table 1 ). In the linkage disequilibrium (LD) analyses, we found that the TSER locus was partially in LD with the TS 3'-UTR delo 
Table 2: TSER and TS 3'-UTR del6 genotype frequencies among breast cancer cases and controls

\begin{tabular}{|c|c|c|c|}
\hline \multirow[t]{2}{*}{ Genotype } & \multirow{2}{*}{$\begin{array}{c}\text { Controls }(\mathrm{N}=473) \\
\mathrm{N}(\%)\end{array}$} & \multicolumn{2}{|c|}{ Breast cancer $(\mathrm{N}=432)$} \\
\hline & & $\mathrm{N}(\%)$ & ${ }^{\mathrm{a} A d j u s t e d ~ O R}(95 \% \mathrm{Cl})$ \\
\hline \multicolumn{4}{|l|}{ TSER } \\
\hline $3 R / 3 R$ (reference) & $305(64.5)$ & $279(64.6)$ & 1.00 \\
\hline $2 R / 3 R$ & $143(30.2)$ & $130(30.1)$ & $0.95(0.70-1.29)$ \\
\hline $2 R / 2 R$ & $25(5.3)$ & $23(5.3)$ & $1.13(0.6 I-2.10)$ \\
\hline $2 R / 3 R$ and $2 R / 2 R$ & $168(35.5)$ & $153(35.4)$ & $0.98(0.73-1.30)$ \\
\hline \multicolumn{4}{|l|}{ TS3'-UTR del6 } \\
\hline del6/del6 (reference) & $216(45.7)$ & 194(44.9) & 1.00 \\
\hline del6/ins6 & $201(42.5)$ & $208(48.1)$ & $1.09(0.82-1.46)$ \\
\hline ins6/ins6 & $56(11.8)$ & $30(6.9)$ & $0.58(0.35-0.97)$ \\
\hline
\end{tabular}

a Adjusted for age, age at menarche, menopausal status, BMI and family history of cancer

locus $\left(D^{\prime}=0.584 ; R^{2}=0.186, P<0.001\right)$. There were four haplotypes derived from the observed TYMS genotypes, but there was no significant difference in the distribution of haplotypes between the cases and controls $(P=0.863)$ (Table 1).

The TSER and TS 3'-UTR del6 genotype distributions in the cases and controls were shown in Table 2. The genotype frequencies for these two polymorphisms were both in agreement with Hardy-Weinberg equilibrium in the controls $\left(\chi^{2}=2.26, \mathrm{df}=1, P=0.13\right.$ for TSER and $\chi^{2}=0.77$, $\mathrm{df}=1, P=0.38$ for TS 3'-UTR del6). The TSER genotype frequencies were $64.5 \%(3 \mathrm{R} / 3 \mathrm{R}), 30.2 \%(2 \mathrm{R} / 3 \mathrm{R})$ and $5.3 \%(2 \mathrm{R} / 2 \mathrm{R})$, respectively, among controls, which were not significantly different from those of the cases $(64.6 \%$ $3 \mathrm{R} / 3 \mathrm{R}, 30.1 \% 2 \mathrm{R} / 3 \mathrm{R}$ and $5.3 \% 2 \mathrm{R} / 2 \mathrm{R})(P=0.999)$. Multivariate logistic regression analyses revealed that both $2 \mathrm{R} /$ $3 \mathrm{R}$ and $2 \mathrm{R} / 2 \mathrm{R}$ genotypes were not significantly associated with breast cancer risk (adjusted OR $=0.95,95 \% \mathrm{CI}=$ $0.70-1.29$ for $2 \mathrm{R} / 3 \mathrm{R}$ and $\mathrm{OR}=1.13,95 \% \mathrm{CI}=0.61-2.10$ for $2 \mathrm{R} / 2 \mathrm{R}$, respectively), compared with the TYMS $3 \mathrm{R} / 3 \mathrm{R}$ genotype, (Table 2). Likewise, the frequencies of TS 3'UTR del6 genotype were $45.7 \%$ (del6/del6), 42.5\% (del6/ ins6), and $11.8 \%$ (ins6/ins6), respectively, in control subjects and 44.9\% (del6/del6), 48.1\% (del6/ins6), and 6.9\% (ins6/ins6), respectively, in breast cancer patients, and the overall difference was statistically significant $(P=0.026)$. Compared with TS 3'-UTR del6/del6 wild-type genotype, a significantly reduced risk was associated with ins6/ins 6 homozygous variant genotype (adjusted OR $=0.58,95 \%$ $\mathrm{CI}=0.35-0.97)$, but it was not related with del6/ins6 heterozygous genotype $(\mathrm{OR}=1.09,95 \% \mathrm{CI}=0.82-1.46)$. (Table 2)

Because age, menopausal status, age at menarche, age at first live birth and family history of cancer were the well accepted risk factors for breast cancer, we performed stratification analyses by these variables to assess risk modification by the TYMS genotypes. We found that reduced breast cancer risk associated with TS 3'-UTR del6 variant genotype was more evident in older women (adjusted OR $=0.53,95 \% \mathrm{CI}=0.28-1.00)$, postmenopausal women (adjusted OR $=0.45 ; 95 \% \mathrm{CI}=0.22-0.90$ ), individuals with a younger first live birth age (adjusted $\mathrm{OR}=0.47$; $95 \%$ CI $=0.22-1.03)$ and individuals with a later menarche age (adjusted OR $=0.39 ; 95 \% \mathrm{CI}=0.19-0.81$ ) (Table 3). However, we did not find any statistical evidence for any interaction on a multiplicative scale between the variant genotypes and potential risk factors of breast cancer (data not shown).

\section{Discussion}

In this hospital-based case-control study, we investigated the associations of one promoter SNP TSER and a TS 3'UTR del6 polymorphism in the 3'-UTR of the TYMS gene with risk of breast cancer in a Chinese population. We found, for the first time, that the TS 3'-UTR ins6/ins6 genotype was associated with a significantly decreased risk of breast cancer, and the associations were more evident in older women, postmenopausal women, individuals with a younger first live birth age and individuals with a later menarche age. These findings suggest that the TS 3'-UTR variant may contribute to the etiology of breast cancer in our Chinese population.

Although the promoter TSER polymorphism was identified in a cis-acting enhancer element of the TYMS gene and is thought to affect TYMS mRNA expression $[16,17,22]$, several molecular epidemiological studies reported contrary results of the associations between this variant and cancer risk [19,23-34]. In the only one study on breast cancer, the TSER variant was found not to contribute to the risk of breast cancer in an Australian population, which is consistent with our current study in Chinese women [27].

The TS 3'-UTR del6 polymorphism is located in the 3'UTR of TYMS gene, and the function of this variant has not yet 
Table 3: Stratified analysis on association between the TS3'-UTR del6 polymorphism and risk of breast cancer

\begin{tabular}{|c|c|c|c|c|c|c|c|}
\hline \multirow[t]{3}{*}{ Variables } & \multirow{3}{*}{$\begin{array}{l}n \text { (cases/ } \\
\text { controls) }\end{array}$} & \multicolumn{6}{|c|}{ TS3'-UTR del6 } \\
\hline & & \multicolumn{3}{|l|}{$\begin{array}{l}\mathrm{n} \text { (cases/ } \\
\text { controls) }\end{array}$} & \multicolumn{3}{|c|}{$\begin{array}{c}\text { aAdjusted OR } \\
(95 \% \mathrm{Cl})\end{array}$} \\
\hline & & del6/del6 & del6/ins6 & ins6/ins6 & del6/del6 & del6/ins6 & ins6/ins6 \\
\hline \multicolumn{8}{|l|}{ Age } \\
\hline$\leq 48$ & $158 / 195$ & $80 / 98$ & $69 / 76$ & $9 / 21$ & 1.00 & I.II(0.70-1.76) & $0.65(0.27-1.56)$ \\
\hline$>48$ & $274 / 278$ & $114 / 118$ & $139 / 125$ & $21 / 35$ & 1.00 & $1.08(0.74-1.58)$ & $0.53(0.28-1.00)$ \\
\hline \multicolumn{8}{|l|}{ Menopausal status } \\
\hline Premenopausal & $197 / 210$ & $93 / 105$ & $90 / 82$ & $14 / 23$ & 1.00 & $1.22(0.80-1.86)$ & $0.75(0.36-1.56)$ \\
\hline Postmenopausal & $235 / 263$ & $101 / 111$ & $118 / 119$ & $16 / 33$ & 1.00 & $1.01(0.68-1.50)$ & $0.45(0.22-0.90)$ \\
\hline \multicolumn{8}{|l|}{ Age at menarche } \\
\hline$<16$ & $239 / 152$ & $103 / 70$ & $117 / 69$ & $19 / 13$ & 1.00 & $1.06(0.68-1.64)$ & $0.87(0.39-1.91)$ \\
\hline$\geq 16$ & $193 / 32 \mid$ & $91 / 146$ & $91 / 132$ & $1 \mathrm{l} / 43$ & 1.00 & $1.13(0.77-1.65)$ & $0.39(0.19-0.81)$ \\
\hline \multicolumn{8}{|c|}{ bAge at first live birth } \\
\hline$\leq 25$ & $166 / 226$ & $70 / 91$ & $85 / 104$ & ||$/ 3 \mid$ & 1.00 & $1.04(0.67-1.61)$ & $0.47(0.22-1.03)$ \\
\hline$>25$ & $253 / 234$ & $116 / 118$ & $120 / 95$ & $|7 / 2|$ & 1.00 & $1.24(0.82-1.87)$ & $0.95(0.45-2.03)$ \\
\hline \multicolumn{8}{|c|}{ Family history of cancer } \\
\hline No & $319 / 378$ & $143 / 173$ & $155 / 165$ & $21 / 40$ & 1.00 & $1.07(0.77-1.48)$ & $0.63(0.35-1.13)$ \\
\hline Yes & $113 / 95$ & $51 / 43$ & $53 / 36$ & $9 / 16$ & 1.00 & $1.27(0.69-2.35)$ & $0.45(0.17-1.21)$ \\
\hline
\end{tabular}

aAdjusted for the other covariates presented in this table in a logistic regression model for each stratum.

b Age at first live birth information was available in 460 controls and 419 breast cancer cases.

been fully understood. Available limited phenotype studies reported that the wild-type del6 allele may be associated with decreased stability of TYMS in vitro, lower intratumoral TYMS expression in vivo and perhaps with increased risk for cancers [35], which is consistent with our present association study that the variant ins 6 allele is associated with a decreased breast cancer risk. Because TYMS plays an important role in folate metabolism, which is essential for DNA methylation, synthesis, and repair, our findings provide some evidence for the underline molecular mechanism of the association between folate metabolism and breast cancer susceptibility.

Recently, a few studies have investigated the association between the TS 3'-UTR del6 polymorphism and risk of several types of cancer, but the results were mixed $[19,23,26,28-30,34]$. Graziano et al found that the TS 3'UTR ins6 allele was protective against gastric cancer in Caucasians [28]. However, three recent studies reported that the TS 3'-UTR ins6/ins6 and/or del6/ins6 +ins6/ins6 genotypes were associated with a significantly increased risk for gastric cancer, SCCNH and lung cancer $[19,23,26]$, while some other studies did not observe any associations between this polymorphism and cancer risk $[29,30,34]$. In the present study, we found, for the first time, that the TS 3'-UTR ins6/ins6 homozygous variant genotype was associated with a significantly decreased risk of breast cancer in a Chinese population, and this significantly protective effect was more evident in postmenopausal women, indi- viduals with a younger first live birth age or individuals with later menarche age. These findings suggest that TYMS polymorphisms may be potential genetic markers of breast cancer risk modified by reproductive hormone levels of the subjects in their lifetime as indicated in menarche age, first live birth age, and menopausal status. However, because of the small sample size in the subgroups, these findings were considered preliminary and need to be validated in further studies with larger sample sizes in these subpopulations. The discrepancies between available association studies in relation to this variant may be due to different etiologies and mechanisms of different cancers, different ethnic backgrounds of populations, uncharacterized environmental exposure factors, and/or potential biases because of the small sample size of related studies.

Genetic polymorphisms often vary between ethnic groups. In the present study in a Chinese population, the frequencies of TSER $3 \mathrm{R} / 3 \mathrm{R}, 2 \mathrm{R} / 3 \mathrm{R}$ and $2 \mathrm{R} / 2 \mathrm{R}$ genotypes were $64.5 \%, 30.2 \%$ and $5.3 \%$, respectively, among 473 control subjects, which were not different from those among the 322 controls in a gastric cancer study in Chinese $(63.0 \% 3 \mathrm{R} / 3 \mathrm{R}, 33.3 \% 2 \mathrm{R} / 3 \mathrm{R}$ and $3.7 \% 2 \mathrm{R} / 2 \mathrm{R}, P=$ $0.447)$ that we previously reported [19]. However, Marsh et al [36] showed a significantly ethnic variation of TSER variant that homozygous triple repeat was twice as common in Chinese subjects (67\%) as in Caucasians (38\%). Similarly, we found that the allele frequency of TS 3'-UTR 
ins 6 was 0.331 among the 473 control subjects, which is also consistent with what was reported in Chinese populations $(0.320, \mathrm{n}=348$ from north China [29], and 0.309, $\mathrm{n}=322$ from southeast China [19]), but it is much lower than that of Caucasians (65\% to $70 \%)[26,30,34]$.

The primary shortcoming of this study is the lack of data on detailed dietary intake of folate, plasma or erythrocyte folate levels and its precursors or metabolites such as homocysteine, which limited our inquiry into potential gene-nutrient interactions in breast carcinogenesis. Furthermore, like all other hospital-based case-control studies, inherited biases may lead to spurious findings or false positive results. Because our cases were from hospitals and the controls were from the community, the study subjects may not be fully representative of the general population. However, we applied rigorous epidemiological designs by limiting factors of selecting subjects and performed further statistical adjustment to minimize these potential biases. The agreement with Hardy-Weinberg equilibrium of these two loci of TYMS gene and similar allele frequencies of our controls to those reported from other Asian populations suggests that the selection bias would not be substantial in terms of genotype distribution. Finally, although we have 94\% statistical power to achieve the main effect of the study, we have very limited power in the stratified analyses because of the small sample size of the subgroups. Therefore, large well-designed studies are warranted to further confirm our findings.

\section{Conclusion}

Our study provides some new evidence that the TS 3'-UTR ins6/ins6 genotype may contribute to the etiology of breast cancer. Studies in diverse ethnic populations and simultaneous measurements of detailed data of the TYMS genotypes as well as its phenotypes, accompanied by multiple SNPs of other important one-carbon metabolism genes and information of folate intake are warranted to further elucidate gene-gene and gene-environment interactions in susceptibility of breast cancer.

\section{Abbreviations}

TYMS, thymidylate synthase; TSER, thymidylate synthase in the 5'-untranslated enhanced region; TS3'-UTR, thymidylate synthase in the 3'-untranslated region; OR, odds ratio; $\mathrm{CI}$, confidence interval; $\mathrm{SNP}$, single nucleotide polymorphism; PCR - RFLP, polymerase chain reaction restriction fragment length polymorphism.

\section{Competing interests}

The author(s) declare that they have no competing interests.

\section{Authors' contributions}

H. S., X. W., F. C. and X. Z. were responsible for the study design, data analyses and interpretation. J. T., J. Q., S. W., $\mathrm{X}$. W. were principally responsible for patients recruitment with assistance from J. G., G. J., J. L. and W. C.. X. Z. and J. G. were responsible for the laboratory work with assistance from G. J. and W. C.. The report was prepared by X. Z. and Z. H., proof read by Q. W. and H. S.. H. S. made the decision to submit the paper for publication and supervised the whole process of the study. All the authors read and approved the final manuscript.

\section{Acknowledgements}

This research was funded by China NationalKey Basic ResearchProgram; Grant number: 2002CB5 I2908; Jiangsu Natural Science Foundation; Grant number: BK2004I45, Postdoctoral Science Foundation of China; Grant number: 2004035218.

\section{References}

I. Yang L, Parkin DM, Ferlay J, Li L, Chen Y: Estimates of Cancer Incidence in China for $\mathbf{2 0 0 0}$ and Projections for 2005. Cancer Epidemiol Biomarkers Prev 2005, 1 4:243-250.

2. Zhang S, Willett WC, Selhub J, Hunter DJ, Giovannucci EL, Holmes MD, Colditz GA, Hankinson SE: Plasma Folate, Vitamin B6, Vitamin B I2, Homocysteine, and Risk of Breast Cancer. J Natl Cancer Inst 2003, 95:373-380.

3. Rohan TE, Jain MG, Howe GR, Miller AB: Dietary folate consumption and breast cancer risk. J Natl Cancer Inst 2000, 92:266-269.

4. Sellers TA, Kushi LH, Cerhan JR, Vierkant RA, Gapstur SM, Vachon CM, Olson JE, Therneau TM, Folsom AR: Dietary folate intake, alcohol, and risk of breast cancer in a prospective study of postmenopausal women. Epidemiology 200I, I 2:420-428.

5. Shrubsole MJ, Jin F, Dai Q, Shu XO, Potter JD, Hebert JR, Gao YT, Zheng W: Dietary folate intake and breast cancer risk: results from the Shanghai breast cancer study. Cancer Res 200I, 61:7|36-7|4|.

6. Kim YI: Folate and carcinogenesis: evidence, mechanisms, and implications. J Nutr Biochem 1999, 10:66-68.

7. Mason JB, Levesque T: Folate: effects on carcinogenesis and the potential for cancer chemoprevention. Oncology (Huntingt) 1996, 10:1727-1736.

8. Ames BN: DNA damage from micronutrient deficiencies is likely to be a major cause of cancer. Mutat Res 200I, 475:7-20.

9. Blount BC, Mack MM, Wehr CM, MacGregor JT, Hiatt RA, Wang G, Wickramasinghe SN, Everson RB, Ames BN: Folate deficiency causes uracil misincorporation into human DNA and chromosome breakage: implications for cancer and neuronal damage. Proc Natl Acad Sci U S A 1997, 94:3290-3295.

10. Duthie SJ: Folic acid deficiency and cancer: mechanisms of DNA instability. Br Med Bull 1999, 55:578-592.

II. Pogribny IP, Basnakian AG, Miller BJ, Lopatina NG, Poirier LA, James $S J$ : Breaks in genomic DNA and within the $p 53$ gene are associated with hypomethylation in livers of folate/methyl-deficient rats. Cancer Res 1995, 55: |894-190|.

12. Fowler BM, Giuliano AR, Piyathilake C, Nour M, Hatch K: Hypomethylation in cervical tissue: is there a correlation with folate status? Cancer Epidemiol Biomarkers Prev 1998, 7:901-906.

13. Sharp L, Little J: Polymorphisms in genes involved in folate metabolism and colorectal neoplasia: a HuGE review. Am J Epidemiol 2004, 159:423-443.

14. Rustum YM, Harstrick A, Cao S, Vanhoefer U, Yin MB, Wilke H, Seeber $S$ : Thymidylate synthase inhibitors in cancer therapy: direct and indirect inhibitors. J Clin Oncol 1997, 1 5:389-400.

15. Hori T, Ayusawa D, Shimizu K, Koyama H, Seno T: Chromosome breakage induced by thymidylate stress in thymidylate synthase-negative mutants of mouse FM3A cells. Cancer Res 1984, 44:703-709.

16. Horie N, Aiba H, Oguro K, Hojo H, Takeishi K: Functional analysis and DNA polymorphism of the tandemly repeated 
sequences in the 5'-terminal regulatory region of the human gene for thymidylate synthase. Cell Struct Funct 1995, 20:191-197.

17. Kawakami K, Omura K, Kanehira E, Watanabe Y: Polymorphic tandem repeats in the thymidylate synthase gene is associated with its protein expression in human gastrointestinal cancers. Anticancer Res 1999, 19:3249-3252.

18. Ulrich CM, Bigler J, Velicer CM, Greene EA, Farin FM, Potter JD: Searching expressed sequence tag databases: discovery and confirmation of a common polymorphism in the thymidylate synthase gene. Cancer Epidemiol Biomarkers Prev 2000, 9: I38I-I 385.

19. Zhang Z, Xu Y, Zhou J, Wang X, Wang L, Hu X, Guo J, Wei Q, Shen $\mathrm{H}$ : Polymorphisms of thymidylate synthase in the $5^{\prime}-$ and 3 'untranslated regions associated with risk of gastric cancer in South China: a case-control analysis. Carcinogenesis 2005, 26:1764-1769.

20. Linkage disequilibrium (LD) estimateing [http://linkage.rock efeller.edu/soft/]

21. Stephens M, Donnelly P: A comparison of bayesian methods for haplotype reconstruction from population genotype data. Am J Hum Genet 2003, 73: I 162-1 I69.

22. Shintani $Y$, Ohta M, Hirabayashi H, Tanaka H, luchi K, Nakagawa K, Maeda H, Kido T, Miyoshi S, Matsuda H: New prognostic indicator for non-small-cell lung cancer, quantitation of thymidylate synthase by real-time reverse transcription polymerase chain reaction. Int J Cancer 2003, 104:790-795.

23. Zhang Z, Shi Q, Sturgis EM, Spitz MR, Hong WK, Wei Q: Thymidylate synthase $5^{\prime}$ - and $3^{\prime}$-untranslated region polymorphisms associated with risk and progression of squamous cell carcinoma of the head and neck. Clin Cancer Res 2004, 10:7903-7910

24. Matsuo K, Ito H, Wakai K, Hirose K, Saito T, Suzuki T, Kato T, Hirai $\mathrm{T}$, Kanemitsu Y, Hamajima H, Tajima K: One-carbon metabolism related gene polymorphisms interact with alcohol drinking to influence the risk of colorectal cancer in Japan. Carcinogenesis 2005, 26:2164-2171.

25. Wang LD, Guo RF, Fan ZM, He X, Gao SS, Guo HQ, Matsuo K, Yin LM, Li JL: Association of methylenetetrahydrofolate reductase and thymidylate synthase promoter polymorphisms with genetic susceptibility to esophageal and cardia cancer in a Chinese high-risk population. Dis Esophagus 2005, 1 8: 177-184.

26. Shi Q, Zhang Z, Neumann AS, Li G, Spitz MR, Wei Q: Case-control analysis of thymidylate synthase polymorphisms and risk of lung cancer. Carcinogenesis 2005, 26:649-656.

27. Grieu F, Powell B, Beilby J, lacopetta B: Methylenetetrahydrofolate reductase and thymidylate synthase polymorphisms are not associated with breast cancer risk or phenotype. Anticancer Res 2004, 24:3215-3219.

28. Graziano F, Kawakami K, Watanabe G, Ruzzo A, Humar B, Santini D, Catalano V, Ficarelli R, Merriman T, Panunzi S, Testa E, Cascinu S, Bearzi I, Tonini G, Magnani M: Association of thymidylate synthase polymorphisms with gastric cancer susceptibility. Int J Cancer 2004, II 2:1010-1014.

29. Zhang J, Cui Y, Kuang G, Li Y, Wang N, Wang R, Guo W, Wen D, Wei L, Yu F, Wang S: Association of the thymidylate synthase polymorphisms with esophageal squamous cell carcinoma and gastric cardiac adenocarcinoma. Carcinogenesis 2004, 25:2479-2485.

30. Chen J, Hunter DJ, Stampfer MJ, Kyte C, Chan W, Wetmur JG, Mosig $\mathrm{R}$, Selhub J, Ma J: Polymorphism in the thymidylate synthase promoter enhancer region modifies the risk and survival of colorectal cancer. Cancer Epidemiol Biomarkers Prev 2003, I 2:958-962.

31. Hishida A, Matsuo K, Hamajima N, Ito H, Ogura M, Kagami Y, Taji H, Morishima Y, Emi N, Tajima K: Associations between polymorphisms in the thymidylate synthase and serine hydroxymethyltransferase genes and susceptibility to malignant lymphoma. Haematologica 2003, 88:159-166.

32. Skibola CF, Smith MT, Hubbard A, Shane B, Roberts AC, Law GR, Rollinson S, Roman E, Cartwright RA, Morgan G]: Polymorphisms in the thymidylate synthase and serine hydroxymethyltransferase genes and risk of adult acute lymphocytic leukemia. Blood 2002, 99:3786-3791.

33. Tan W, Miao X, Wang L, Yu C, Xiong P, Liang G, Sun T, Zhou Y, Zhang $X, \mathrm{Li} \mathrm{H}$, Lin D: Significant increase in risk of gastroesophageal cancer is associated with interaction between promoter polymorphisms in thymidylate synthase and serum folate status. Carcinogenesis 2005, 26: I430- 1435.

34. Ulrich CM, Bigler J, Bostick R, Fosdick L, Potter JD: Thymidylate synthase promoter polymorphism, interaction with folate intake, and risk of colorectal adenomas. Cancer Res 2002, 62:336I-3364.

35. Mandola MV, Stoehlmacher J, Zhang W, Groshen S, Yu MC, lqbal S, Lenz HJ, Ladner RD: A 6 bp polymorphism in the thymidylate synthase gene causes message instability and is associated with decreased intratumoral TS mRNA levels. Pharmacogenetics 2004, 14:319-327.

36. Marsh S, Collie-Duguid ESR, Li T, Liu X, McLeod HL: Ethnic variation in the thymidylate synthase enhancer region polymorphism among Caucasian and Asian populations. Genomics 1999, 58:310-312.

\section{Pre-publication history}

The pre-publication history for this paper can be accessed here:

http://www.biomedcentral.com/1471-2407/6/138/pre pub
Publish with Bio Med Central and every scientist can read your work free of charge

"BioMed Central will be the most significant development for disseminating the results of biomedical research in our lifetime. "

Sir Paul Nurse, Cancer Research UK

Your research papers will be:

- available free of charge to the entire biomedical community

- peer reviewed and published immediately upon acceptance

- cited in PubMed and archived on PubMed Central

- yours - you keep the copyright 